\title{
Venezuela ante la fatalidad de los arbitrajes
}

J. Eloy Anzola

\section{Sumario}

1. ¿Qué ocurre? 2. ¿Cuándo se conocerán las condenas? 3. ¿A cuánto ascenderán las condenas? 4. ¿Pagará Venezuela las condenas? 5. ¿Qué puede hacer Venezuela contra esos laudos si le son claramente adversos porque los montos de las condenas son muy elevados? 6. ¿Podría Venezuela alegar errores del laudo? 7. ¿Puede Venezuela solicitar aclaratorias de los laudos? 8. ¿Puede Venezuela pedir la revisión del laudo? 9.¿Puede Venezuela pedir la anulación del laudo? 10. ¿Qué valor tiene el laudo cuando queda firme? 11. ¿Qué puede ocurrir si Venezuela se niega a pagar? 12. ¿El inversionista vencedor puede cobrar en Venezuela? 13. ¿Qué bienes pueden ser embargados o ejecutados fuera de Venezuela? 14. ¿Qué bienes están amparados por inmunidad soberana? 15. ¿Son embargables o ejecutables el oro y las divisas que estén a nombre del Banco Central de Venezuela? 16. ¿Puede ser embargado o ejecutado el avión del presidente de la República? 17. ¿Pueden ser embargados o ejecutados bienes de PDVSA ubicados fuera de Venezuela? 18. ¿Qué pasa si Venezuela se retira del CIADI? 19. ¿Exxon-Mobil inició un arbitraje ante la CCI contra PDVSA? 20. ¿Podría Venezuela negociar un acuerdo o una transacción con estas empresas?

\section{1. ¿QUÉ OCURRE?}

Venezuela quedará condenada en las próximas semanas o meses a pagar miles de millones de dólares en los arbitrajes que en su contra le siguen filiales de Conoco-Phillips ${ }^{1}$ y Exxon- 
Mobil2. En el futuro también puede quedar condenada por montos elevados en otros procesos arbitrales, además de los petroleros.

Como es bien sabido, el gobierno de Venezuela, ha tomado posesión de instalaciones petroleras, plantas industriales, fincas en explotación y otros bienes propiedad de inversionistas extranjeros (también de nacionales, pero esa es otra historia). En muchos de esos casos el gobierno venezolano, ignorando su propia Constitución y normas internacionales, no ha pagado compensación alguna o ha propuesto montos tan bajos, que los inversionistas extranjeros los han rechazado. Es el caso de Exxon-Mobil y Conoco-Phillips que fueron desposeídas de operaciones e instalaciones petroleras, entre ellas las que tenían en el país para extraer, mejorar y comercializar crudos provenientes de la Faja del Orinoco ${ }^{3}$.

Venezuela, en adición a su legislación interna, ha suscrito desde 1990 hasta la fecha unos veinticinco tratados internacionales -llamados tratados bilaterales de protección y promoción de inversiones, que identificaremos como TBPPI- que garantizan a los inversores extranjeros provenientes de los países signatarios de esos tratados, el pago de compensaciones adecuadas en caso de expropiación.

Los TBPPI confieren además a esos inversionistas el derecho a reclamar contra Venezuela las indemnizaciones que crean ade-

1. Fue iniciado ante el CIADI el 13 de diciembre de 2007 por Conoco Phillips Company y otras contra la Repuublica Bolivariana de Venezuela, Caso CIAD] N'ARB 07/30.

2. Son dos procesos arbitrales: el primero, que comenzó el 6 de sepliembre de 2007 ante el Centro Intemacional de Arreglo de Diferencias Relativas a Inversiones (CIADI) iniciado por Mobil Corporation, Venezucla Holdings BV, Mobil Cerro Negro Holding LTD. Mobil Venezolana de Petróleo Holdings Inc., Mobil Cerro Negro Limited y Mobil Venczolana de Petróleo Inc. contra la República Bolivariana de Venezuela, Caso CIADI N ARB 07/27; y el segundo, de naturaleza comercial administrado por la Corte Internacional de Arbitraje de la Cảmara de Comercio Internacional iniciado el 25 de enero de 2008, por Mobil Cerro Negro LTD conira PDVSA Cerro Negro, S. A y PDVSA, Caso CCI N" 15416/JRF.

3. La llamada Faja del Orinoco es un enorme rescrvorio de petróleo ubicado en el centro de Venezucla. al norte del rio que lleva ese nombre. En su mayor parte es de petróleo pesado (10 $\mathrm{APl}$ que requiere de un proceso de mejora para hacerlo comercial. La inversion en los "mejoradores" es muy cuantiosa. 
cuadas en arbitrajes internacionales que administra el Centro Internacional de Arreglo de Diferencias Relativas a Inversiones (CIADI). Es lo que han hecho Exxon-Mobil y Conoco-Phillips, empresas de origen estadounidense, que canalizaron sus inversiones a través de los Países Bajos (Holanda) con quien Venezuela tenía suscrito un TBPPI ${ }^{4}$, dado que Venezuela y EE. UU., no han suscrito un tratado de esa naturaleza.

A su vez, El CIADI fue creado por un tratado internacional -el Convenio CIADI- cuyo texto quedó redactado en $1965 \mathrm{y} \mathrm{al}$ que Venezuela se adhirió en 19955. El CIADI es un brazo independiente del Banco Mundial. Los inversionistas pueden acudir al CIADI e iniciar procesos arbitrales contra los estados que hayan violado sus derechos. Al amparo del CIADI se constituyen los tribunales arbitrales que deciden estos casos y están integrados, normalmente, por tres miembros, uno escogido por el inversionista reclamante, otro por el estado demandado y un tercero, de mutuo acuerdo, o en su defecto, por el presidente del CIADI6. Los procesos terminan con una sentencia o laudo arbitral.

Venezuela ha sido demandada en unos veintidós procesos arbitrales de esta naturaleza. Los más sonados, por ser los más cuantiosos, son los intentados por Exxon-Mobil y Conoco-Phillips.

Además de estos arbitrajes contra la República de Venezuela, una filial de Exxon-Mobil, la Mobil Cerro Negro Limited, ha demandado a PDVSA Cerro Negro, S.A. y a Petróleos de Venezuela, S.A. (PDVSA) ${ }^{7}$, en un arbitraje que se lleva bajo

4. El TBPPI entre Venezuela y los Paises Bajos está publicado en la Gaceta Oficial venezolana (en lo sucesivo, G.O.), N 35.269 del 26 de agosto de 1993. Tenia una vigencia de 15 años (Articulo 14.1) A su vencimiento Venezuela optó por no renovarlo. No obstante, las protecciones que acuerda el Tratado continúan por 15 años adicionales para la inversiones hechas antes de la terminación del Tratado.

5. G.O. $\mathrm{N}^{\circ} 35.685 \mathrm{del} 3 \mathrm{de}$ abril de 1995.

6. Articulos 37 y 38 del Convenio CIADI.

7. Petróleos de Venczuela, S.A. (PDVSA) es la empresa matriz petrolera. Tiene un solo accionista la República de Venezuela. 
las reglas de la Corte Internacional de Arbitraje de la Cámara de Comercio Internacional (CCI ${ }^{8}$. La demanda guarda relación con los mismos hechos de la expropiación sin compensación; más adelante nos referiremos a este asunto.

\section{2. ¿CuÁndo SE Conocerán las CONDENAS?}

No hay fecha fijada.

En el CIADI, el caso Conoco-Plillips está más avanzado. En la página web del CIADI ${ }^{9}$ se indica que a mediados de 2010 tuvieron lugar las audiencias sobre los temas de fondo. No hay más información, de lo que puede deducirse que los árbitros han de estar deliberando sobre el contenido del laudo.

En el caso de Exxon-Mobil en el CIADI, la página red indica que el 15 de septiembre de 2011, la parte demandante ha presentado una respuesta a temas de fondo. Aún no han tenido lugar las audiencias sobre los temas sustanciales. Por tanto, la decisión no verá la luz tan pronto.

Sobre el caso que lleva la filial de Exxon-Mobil ante la CCI, no hay ninguna información pública que sea confiable porque estos arbitrajes son confidenciales. Se asume por el tiempo que ha transcurrido desde su inicio, que el proceso ha de estar en su fase final.

8. Fue iniciado el 25 de enero de 2008, por Mobil Cerro Negro LTD contra PDVSA Cerro Negro, S.A. y PDVSA, Caso CCI N" 15416/JRF. Los detalles de estos arbitrajes son confidenciales, sin embargo, Hildegard Rondén de Sansó da cuenta del mismo y aporta algunas informaciones en su obra, El Régimen Juridico de los Hidrocarburos, Caracas 2008, p. 436 y sgtes.

9. htip:/icsid. worldbank org/CSID/FrontServlet (consultado el 1" de octubre de 2011) 


\section{3. ¿A CuÁNTo ASCENDERÁn las CONDENAS?}

Los laudos arbitrales fijarán el monto de la compensación que ha de pagar nuestro país.

Los precedentes que existen indican que las indemnizaciones que ordenarán los tribunales arbitrales tomarán en cuenta el valor de las empresas en marcha (going concern value). Puede tratarse del valor de mercado de la inversión antes de la nacionalización (market value); o de un valor que capitalice los beneficios esperados o los flujos de efectivo esperados, aplicándoles una tasa de descuento (discounted cash flow). En todo caso el avalúo será, sin duda, mucho más elevado que el valor en libros (book value) que Venezuela ha ofrecido pagar a Exxon-Mobil y a ConocoPhillps.

Es decir, es muy probable que Venezuela quede condenada a pagar más de lo que su gobierno quiere, aunque por ahora desconocemos los montos exactos.

Barclays Capital estima que por los dos casos que aquí revisamos, la cifra alcanzaría a 12.700 millones de dólares ${ }^{10}$. No sabemos si esa información es certera, porque los procesos arbitrales son confidenciales, se conocerá el monto, de manera oficial, cuando se publiquen los laudos.

\section{4. ¿Pagará Venezuela las condenas?}

Hasta ahora ningún vocero oficial ha dicho si Venezuela pagará las condenas o pretenderá desconocerlas, salvo de algunas voces altisonantes.

El gobierno anuncia medidas, como la repatriación del oro y la movilización de las reservas líquidas del Banco Central de 10. Diario El Universal, Caracas, 23 de septiembre de 2011. 
Venezuela (BCV) a bancos de China y Rusia que algunos interpretan -erradamente a nuestro juicio- como prevenciones ante la inminencia de los laudos adversos.

Abundan los rumores sobre lo que Venezuela hace ahora y hará más adelante para reducir o excluir el impacto de las próximas condenas.

\section{5. ¿QuÉ PUede hacer Venezuela contra esos laU- DOS SI LE SON CLARAMENTE ADVERSOS PORQUE LOS MONTOS DE LAS CONDENAS SON MUY ELEVADOS?}

El Tratado del CIADI es categórico: el laudo, al hacerse firme, se hace obligatorio para las partes y no podrá ser objeto de apelación ni de otros recursos. La misma norma agrega que las partes acatarán el laudo y lo cumplirán en todos sus términos ${ }^{11}$.

Si bien el laudo se hace obligatorio desde el mismo día que sea remitido a las partes, Venezuela podría evitar su ejecución inmediata. Venezuela podría señalar posibles errores de cálculo o aritméticos en el laudo y pedir que se rectifiquen; también podría solicitar aclaratorias acompanadas de una petición de suspensión temporal de la ejecución del laudo; también puede pedir la revisión del laudo por la aparición de un nuevo hecho, desconocido antes y que no se haya considerado en el debate arbitral; $y$, finalmente, pedir lo más radical, la anulación del laudo. Veamos cada una de estas posibilidades.

\section{6. ¿Podría Venezuela alegar errores del laudo?}

El Convenio CIADI y las Reglas de Arbitraje del CIADI facultan a las partes para requerir un pronunciamiento del

11. Articulo 53 (1) del Convenio CIADI. 
mismo tribunal arbitral (u otro, si aquel no puede reunirse) sobre algún punto omitido en el laudo; también se le puede pedir que rectifique errores materiales, aritméticos o similares del mismo ${ }^{12}$.

Estas peticiones hay que presentarlas dentro de los cuarenta y cinco días siguientes a la fecha en que se haya dictado el laudo y se convocará al tribunal arbitral para que conozca de ellas y las decida. Si bien no está prevista la suspensión formal de la ejecución del laudo, es normal que el vencedor espere a que el asunto se termine antes de exigir el pago de manera compulsiva.

Como vemos, con estas solicitudes se pueden ganar algunas semanas pero la decisión no cambiará para nada el efecto principal del laudo, como es la condena a pagar una elevada compensación.

\section{7. ¿Puede Venezuela solicitar aclaratorias de LOS LAUDOS?}

Venezuela también podría pedir aclaratorias sobre el contenido del laudo, lo que sí puede dar lugar a una suspensión formal, obviamente temporal, de la ejecución del laudo hasta tanto queden ellas resueltas por el tribunal arbitral. Esa suspensión de la ejecución del laudo habrá de acordarla, si la encuentra justificada, el mismo tribunal arbitral ${ }^{13}$.

Al igual que en la hipótesis anterior, la solicitud de aclaratorias y su decisión no afectará el contenido sustancial del laudo, que es la condena al pago de una indemnización.

12. Articulos 49, 50 y 51 del Convenio CIADI; Reglas 49, 50 y 51 de las Reglas de Arbitraje CIADI.

13. Articulos 50 del Convenio ClADI. 


\section{8. ¿Puede Venezuela pedir la revisión del laudo?}

Las partes pueden pedir también que se revise el laudo fundadas en el descubrimiento de un hecho que hubiera podido influir de modo decisivo en el laudo y siempre que, al tiempo de dictarse el laudo, hubiere sido desconocido por el tribunal arbitral y por la parte que inste la revisión, y que el desconocimiento de ésta no se deba a su propia negligencia14. La solicitud de revisión ha de plantearse dentro de los noventa días al día en que fue descubierto el hecho' ${ }^{15}$.

Como vemos ésta es una situación muy excepcional y es difícil imaginar cómo podría plantearse en los casos que revisamos.

\section{9. ¿Puede Venezuela pedir la anulación del LAUDO?}

Dentro de los ciento veinte días siguientes a la fecha del laudo, las partes pueden solicitar la nulidad del laudo, que será decidida no por el mismo tribunal arbitral, sino por una comisión ad-hoc integrada por tres personas que designará el presidente del CIADI. La comisión puede, si lo estima adecuado, suspender la ejecución del laudo mientras estudia y decide la anulación ${ }^{16}$.

La anulación del laudo puede solicitarse únicamente por las siguientes razones ${ }^{17}$ :

(a) que el Tribunal se hubiere constituido incorrectamente;

(b) que el Tribunal se hubiere extralimitado manifiestamente en sus facultades;

14. Artículos 51 (1) del Convenio CIADI.

15. Articulos 51(2) del Convenio ClADI.

16. Articulo 52 del Convenio CIADI.

17. Articulo 52(1) del Convenio ClADl.

Revista Ecuatoriana de ARbitraje 
(c) que hubiere habido corrupción de algún miembro del Tribunal;

(d) que hubiere quebrantamiento grave de una norma de procedimiento; 0

(e) que no se hubieren expresado en el laudo los motivos en que se funde.

Las causas de anulación son estrictas y no se trata de una apelación donde se vuelve a revisar el fondo de la decisión. $\mathrm{Al}$ contrario, hay que alegar alguna de esas causales, que como se ve se dan en situaciones bastante extraordinarias. Por el momento es imposible saber si alguna de estas situaciones extremas pueda darse o si los laudos puedan tener las fallas que justifiquen una anulación. Hay que esperar a la publicación de los mismos para hacer el análisis correspondiente. Será entonces cuando Venezuela pueda evaluar si hay razones para intentar acciones de esa naturaleza.

Acotemos que Argentina -junto con Venezuela es uno de los países más demandados ante el CIADI-intentó con éxito procedimientos de anulación en los casos Sempra y Enron ${ }^{18}$. Pero debe advertirse que los casos argentinos en nada se parecen a las expropiaciones venezolanas.

Si un recurso de anulación es declarado con lugar, el laudo quedará anulado y sin efecto. En ese caso, las partes pueden solicitar que el asunto se someta a un nuevo tribunal arbitral. Es decir, el inversionista podrá iniciar un segundo arbitraje.

Agotadas las vías de rectificaciones, revisiones y aclaratorias, y si no se intenta la anulación, o si ésta es declarada sin lugar, el laudo quedará firme y se hará ejecutable.

18. Sempra Encrgy International contra Argentina, Caso CIADI ARB 02/16, decisión del 29 de junio de 2010; Enron Corporation y Ponderosa Assets, L.P. contra Argentina, Caso CIADI ARB/01/3, decisión del 30 de Julio de 2010. 


\section{0. ¿QUÉ VALOR TIENE EL LAUDO CUANDO QUEDA FIRME?}

Si Venezuela es vencida y el laudo se hace firme, quedará obligada a pagar las sumas de dinero que ordenen los laudos.

Si Venezuela paga total y oportunamente el monto de la condena, se acaba el asunto.

\section{1. ¿Qué PUede ocurRir Si Venezuela SE NIEgA A PAGAR?}

El Convenio CIADI indica que todo Estado Contratante -lo que incluye a un número importante de países, entre ellos Venezuela, Estados Unidos, China y casi todos los países europeos- reconocerá al laudo carácter obligatorio y hará ejecutar a solicitud del interesado, dentro de sus territorios, las obligaciones pecuniarias impuestas por el laudo, como si se tratase de una sentencia firme dictada por un tribunal existente en dicho Estado ${ }^{19}$.

Esto significa que el inversionista vencedor puede acudir a cualquier país signatario del Convenio CIADI e intentar el reconocimiento y la ejecución del laudo. Por tanto, si Venezuela se niega a pagar, el beneficiario de la condena puede acudir a tribunales de distintos países, como los antes nombrados, solicitar el reconocimiento de los laudos y solicitar embargos, $\mathbf{u}$ otras medidas ejecutivas, contra bienes de la República.

19. Articulo 54(1) del Convenio ClADI. 


\section{2. ¿EL INVERSIONISTA VENCEDOR PUEDE COBRAR EN VENEZUELA?}

El inversionista puede también ir a Venezuela a exigir el cumplimiento de las sentencias arbitrales. Pero la República está amparada en el territorio venezolano por privilegios que impiden el embargo de sus bienes o medidas ejecutivas contra ellos ${ }^{20}$. $\mathrm{El}$ acreedor deberá entonces contentarse con seguir el procedimiento para acreencias no prescritas que prevén las leyes venezolanas ${ }^{21}$. Éste no luce como un camino muy atractivo.

Argentina ha señalado a los inversores que han obtenido laudos a su favor que, para hacerlos efectivos, deben acudir a Argentina y hacer allí los trámites administrativos y judiciales necesarios ${ }^{22}$. Los inversores alegan que la posición argentina se aparta de las normas del Convenio CIADI al no acatar y cumplir voluntariamente los laudos que le son adversos. La Convención CIADI prevé que en estos casos el inversor afectado puede pedir a su gobierno que le conceda protección diplomática frente al Estado transgresor ${ }^{23}$. Así lo han hecho las empresas estadounidenses Azurix y Blueridge y el gobierno norteamericano ha anunciado que sus funcionarios no votarán a favor de otorgar créditos a Argentina en el Banco Mundial y en el Banco Interamericano de Desarrollo24. Las empresas han pedido que Argentina sea retirada del sistema general de preferencias que ampara a las importaciones a Estados Unidos provenientes de aquel país pero todavía no ha habido pronunciamiento al respecto.

20. Artículo 73 de la Ley Orgainica de la Procuraduria General de la República, G.O. N* 5.554 Extraordinario del $13 \mathrm{de}$ noviembre de 2001.

21. Articulo 86.1 de la misma Ley.

22. BALDWIN Edward. Mark KANTOR and Michacl NOLAN Limits to Enforeement of ICSID Awards, 23 Journal of International Arbitration (1): 1-24, 2006; Irina Natacha Gedwillo. The Enforcement of ICSID Awards Before Argentinc Courts, Transnational Dispute Management, Mayo 2011 (www, transnational-dispute-management com).

23. Articulo 27(1) del Convenio CIADI.

24. En latinews com del 11 de agosto de 2011; en http://economia.terra com ar noticias/noticia aspx?idNoticia $=201109192116$ EFE 16518547 , del 19 de septicmbre de 2011; y en Diario Clarin. Bucnos Aires, 28 de septiembre de 2011. 


\section{3. ¿QUÉ BIENES PUEDEN SER EMBARGADOS O EJECUTA- DOS FUERA DE VENEZUELA?}

Pueden ser objeto de ejecución bienes que sean propiedad de la República ubicados en el extranjero y que no estén amparados por inmunidad soberana. El Convenio CIADI aclara que las normas de inmunidad soberana no están derogadas ${ }^{25}$.

Las reglas de inmunidad soberana no son absolutas, pueden renunciarse, como ocurre con frecuencia para préstamos internacionales, pero Venezuela, que se sepa no ha renunciado a su inmunidad soberana para estos casos.

\section{4. ¿QUÉ BIENES ESTÁN AMPARADOS POR INMUNIDAD SOBERANA?}

Las leyes de inmunidad soberana no son iguales en todos los países ${ }^{26}$, pero hay algunas reglas básicas bastante uniformes.

$\mathrm{Ni}$ las sedes de embajadas o consulados, ni su mobiliario, ni las cuentas bancarias de estas entidades, pueden ser objeto de medidas preventivas o ejecutivas. Son inembargables por disposiciones legales internas, como las británicas y estadounidenses y, también, por tratados internacionales.

Solamente son embargables los bienes de la República que estén dedicados a actividades comerciales.

25. Articulo 55 del Convenio ClADI.

26. Los Estados Unidos promulgó en 1976 el Forcign Sovcreign inmunitics Act y El Reino Unido dictó en $1978 \mathrm{el} \mathrm{State} \mathrm{Inmunity} \mathrm{Act.}$ 


\section{5. ¿SON EMBARgables O EJECUTABles EL ORO Y LAS divisas QUE ESTÉN A NOMBRE DEL BANCO CENTRAL de Venezuela?}

No lo son. Las cuentas de los bancos centrales con depósitos en divisas $u$ oro que constituyen reservas internacionales no son embargables. Pertenecen a una entidad distinta a la República y son considerados bienes públicos $\mathrm{y}$, por tanto, están protegidos por inmunidad soberana. Se estima que no están dedicados a actividades comerciales.

El anunciado traslado a Venezuela del oro hoy depositado por el Banco Central venezolano en bancos o instituciones extranjeras no se justifica porque los vencedores de los arbitrajes puedan embargarlo o ejecutarlo. De la misma manera que tampoco se justifica el traslado de divisas propiedad del Banco Central venezolano a bancos de Rusia, China, y otros países. Ni el oro ni las divisas propiedad del Banco Central de Venezuela son embargables en los países donde hoy se encuentran como Estados Unidos, el Reino Unido y países europeos.

\section{6. ¿Puede ser embargado o ejecutado el avión del Presidente de la República?}

No puede serlo. Es de asumirse que el avión pertenece a la fuerza aérea venezolana y los bienes militares están protegidos por inmunidad soberana. En una ocasión se intentó embargar el avión de la presidencia argentina cuando acudió en el año 2007 a Estados Unidos para su mantenimiento y la solicitud fue finalmente desechada por un tribunal estadounidense ${ }^{27}$.

27. Michele Colella and Denise Dussault, v. The Republic of Argentina, F. Supp.2d, 2007 WL 1545204 (N.D.Cal.). 


\section{7. ¿Pueden ser embargados o ejecutados bienes DE PDVSA UBICADOS FUERA DE VENEZUEla?}

Cuando la condenada sea la República, como ocurrirá en los casos CIADI, la primera respuesta es no, porque PDVSA es una persona jurídica distinta a la República. Además, activos muy importantes de PDVSA, como lo es CITGO que tiene sus activos en Estados Unidos, son a su vez de subsidiarias de PDVSA. Están así más distantes de la República.

El acreedor puede tener éxito, no obstante, si prueba, ante los tribunales del país a los que acuda a exigir el cumplimiento del laudo, que entre la República y PDVSA (y sus subsidiarias) hay una unidad de gestión y administración que convierte a la segunda en una entidad inseparable de la primera y que, por tanto, hay una identidad administrativa, financiera y jurídica entre ambas.

El acreedor hará notar que la República es el único accionista de PDVSA, que el ministro de energía es su presidente, que los siete miembros de su directorio los designa mediante decreto el presidente de la República ${ }^{28}$ y que PDVSA no goza de autonomía alguna, que toda su gestión la dirige el gobierno nacional. Alegará también que PDVSA es utilizada por el gobierno nacional para numerosas tareas que son propias de éste y no de una empresa independiente dedicada de manera separada a la actividad petrolera.

Esos han sido los criterios que han seguido los tribunales de distintos países para decretar embargos y ejecuciones contra empresas petroleras u otras propiedades de algún estado, cuando el estado ha sido condenado. Cuando no se ha comprobado la identidad entre la empresa y el estado propietario, los tribunales han rechazado acordar medidas ejecutivas contra bienes de esas empresas.

28. Clảusula Décima Séptima de los Estatutos de PDVSA (Ver en:

http:/www pdvsa.com/index.php?tpl=interface. sp/design readmenu.tpl.htm!\&newsid obj id $=76 \&$ n ewsid temas $=6$, consulkado en septicmbre de 2011). 
En cambio, cuando se dan circunstancias parecidas a las descritas, han habido decisiones que han acordado medidas ejecutivas contra empresas estatales. Así, la Corte de Apelaciones de París acordó embargos sobre bienes de empresas petroleras pertenecientes a un estado, no habiendo sido ellas las condenadas, en tres ocasiones en el año 2003, en el de la empresa petrolera de la República del Congo y, de nuevo, en 2004 contra la empresa petrolera de Camerún ${ }^{29}$. Los mismos criterios se acogieron en Estados Unidos en la sentencia de la Corte Suprema el 17 de junio de 1983 en el caso First National City Bank v. Banco para el Comercio (Cuba) ${ }^{30}$, al igual que en Inglaterra, en el caso Trendex Trading Corporation v. Central Bank of Nigeria ${ }^{31}$, si bien no se trataba de activos petroleros.

No se puede ser categórico, pero los bienes de PDVSA en Estados Unidos y en otros países, pueden estar expuestos a medidas ejecutivas en caso de que Venezuela se niegue a pagar los laudos.

\section{8. ¿QUé PASA Si Venezuela se Retira del CIADI?}

No tendría en lo inmediato ningún efecto beneficioso. Los procesos arbitrales en curso no se verían afectados de manera alguna, seguirían su curso. El retiro efectivo del CIADI se produciría a los seis meses del anuncio ${ }^{32}$. Además, las reclamaciones que se intenten en el futuro, si Venezuela sale del CIADI, podrán iniciarse en otros centros de arbitraje distintos al CIADI, como lo prevén muchos de los TBPPI suscritos por Venezuela.

29. Ver Statc Entitics in Intcrnational Arbitration, editado por E. Gaillard y J. Younan, IAI. Nucva York, 2008, p. 190.

30. 103 S. Ct. 2591 (1983); en la misma obra de E. Gaillard y J. Younan. p. 559.

31. [1977] I Q.B. 529, 560; en la misma obra de E. Gaillard y J. Younan, p. 139.

32. Articulo $71 \mathrm{del}$ Convenio CIADt. 


\section{9. ¿EXXON-Mobil INICIÓ UN ARBITRAJE ANTE LA CCI CONTRA PDVSA?}

Sí, una empresa filial de Exxon-Mobil, Mobil Cerro Negro LTD., acudió ante la Corte Internacional de Arbitraje de la Cámara de Comercio Internacional (CCI) e inició un arbitraje contra PDVSA Cerro Negro, S.A. y PDVSA, el 25 de enero de 2008. De conformidad con las Reglas de Arbitraje de la CCI, se constituyó un tribunal arbitral con tres miembros que en la actualidad conoce de este proceso. En buena medida, el arbitraje trata también de la expropiación ordenada por el gobierno venezolano sobre las instalaciones de la Mobil en Cerro Negro, en la faja del Orinoco, pero la reclamación se hace en un contexto jurídico diferente.

Alega la demandante que en el contrato de asociación para la explotación del campo Cerro Negro en la faja del Orinoco y la construcción de un mejorador en José, Estado Anzoátegui, contrato que se firmó en 1997 entre Mobil Cerro Negro LTD. y PDVSA Cerro Negro, la última convino en indemnizar a la primera por cualquier medida discriminatoria que tomara el gobierno venezolano contra ella, lo que incluye el pago de una indemnización por la expropiación de sus instalaciones si el gobierno venezolano no le pagaba una compensación adecuada. En el mismo contrato, PDVSA convino en garantizar estas obligaciones asumidas por su filial PDVSA Cerro Negro.

Por lo tanto, las acciones son contra la filial y PDVSA, no contra la República. En consecuencia, si el laudo es favorable a la filial de Exxon-Mobil, ésta se dirigirá contra PDVSA y sus bienes directamente para hacer efectivo el pago.

Cabe recordar que antes de iniciarse este arbitraje, la demandante acudió a un tribunal federal en la ciudad de Nueva York que acordó un embargo sobre fondos de PDVSA por trescientos millones de dólares. La decisión fue confirmada el 28 de febrero de $2008^{33}$ y subsiste hasta el día de hoy. De la misma 
manera acudió a un tribunal londinense que el 24 de enero de 2008 acordó una orden de congelamiento (Mareva Injunction) de bienes de PDVSA por un monto de doce mil millones de dólares $^{34}$. El mismo tribunal, pero con otro juez de titular, revocó la orden el 28 de marzo de 2008.

Este caso no es un arbitraje de inversiones, sino un arbitraje de naturaleza comercial. Por tanto, para el reconocimiento del laudo y su ejecución a nivel internacional, se aplicarán las normas de dos tratados internacionales también suscritos y ratificados por Venezuela. En primer lugar, la Convención de Nueva York de $1958^{35}$ adoptada por ciento cuarenta y dos países, incluidos EE.UU. y los países europeos, China y Rusia; y, en segundo lugar, la Convención de Panamá de $1975^{36}$ adoptada por muchos países del continente, incluido EE.UU. Ambos textos, en lo que aquí interesa, son muy semejantes.

De acuerdo con esas normas, si el laudo es adverso a PDVSA, ésta podría, por causales específicas señaladas en las citadas Convenciones, oponerse a la ejecución del laudo cuando la filial de Exxon-Mobil intente ante los tribunales estadounidenses u otros, el reconocimiento del laudo y quiera proceder contra bienes propiedad de la petrolera venezolana. No será fácil hacerlo, en el mundo de hoy los tribunales de los estados firmantes de esas convenciones, especialmente la de Nueva York, son reacios a admitir oposiciones a la ejecución de los laudos. Por ello, el camino de oposición será espinoso.

PDVSA podría intentar la nulidad del laudo en la ciudad sede del arbitraje, que es Nueva York. La nulidad se intenta ante los tribunales judiciales y procede por causas muy específicas, normalmente difíciles de establecer. Sin conocer el contenido del

33. US District Court for the Southem District of New York, Mobil Cerro Negro Lid, v. PDVSA Cerro Negro. S.A. (Case 1:07-cv-11590-DAB).

34. Hihgh Court of Justice, Queen's Bench Division, Commercial Court, Claim No. 2008 Folio 61.

35. Su nombre completo es Convención sobre el Reconocimicnto y la Ejecución de la Sentencias Arbitrales Extranjeras, publicada en Venezucla en la G.O. Extr. N" 4832, 29 de diciembre de1994.

36. Su nombre completo es Convención Inıcramericana de Arbitrajc, publicada en Venezuela en ta G,O. $N^{\circ} 33170,22$ de febrero de 1985. 
laudo, es imposible determinar si la oposición o la anulación podrían justificarse.

Se han hecho estimaciones acerca del monto de esta condena. Se afirma que podría ser tres mil setecientos mil millones de dólares ${ }^{37}$, otros hablan de cifras mucho mayores. De nuevo, los procedimientos arbitrales son confidenciales y no se sabrá el monto verdadero sino al momento de conocerse el laudo.

No es razonable que la República y PDVSA paguen dos condenas separadas que nazcan de los mismos hechos y que acuerden compensaciones por las mismas causas. Se habla -sin que hayamos podido confirmarlo- que ha habido un acuerdo, o quizá una decisión arbitral, para que Exxon-Mobil, eventual vencedor, escoja la ejecución de alguno de los laudos que le sean favorables y no pueda exigir el cumplimiento de ambas condenas.

\section{0. ¿Podría Venezuela negociar un acuerdo o una TRANSACCIÓN CON ESTAS EMPRESAS?}

Sí, esa posibilidad está siempre abierta, aunque el ministro venezolano de energía y presidente de PDVSA ha negado la posibilidad de negociaciones directas con Exxon-Mobil.

37. Barclays Capital, diario El Nacional, Caracas, 14 de abril de 2011. 